\title{
Influence of intellectual impairment (II) on basketball players' capacity to solve a game situation: towards evidence-based classification systems in II-basketball
}

\section{Javier PINILLA*, Javier PÉREZ-TEJERO*, Javier SAMPEDRO*, Ignacio REFOYO*, Alberto LORENZO*, Jorge LORENZO*, Debbie VAN BIESEN** \& Yves VANLANDEWIJCK**}

(*) Technical University of Madrid, Spain (**) KU Leuven, Belgium.

(Received on April 7, 2016; Accepted on June 2, 2016)

\begin{abstract}
Basketball for athletes with intellectual impairment (II) requires the development of evidence-based eligibility systems to guarantee that only athletes with significant limitations performing basketball participate in these competitions. In addition, this is needed to re-include IIbasketball in the Paralympic program. To do this, it is required to investigate how II impacts on fundamental basketball activities. To address this need, the aim of this study was to compare ablebodied (AB) and II-players' capacity to solve a game situation. A field test was designed ad hoc in which 38 elite II-players from France, Portugal, Australia and Japan who participated in the Global Games (2015) and 38 AB-basketball players competing in Spanish competitions, had to solve 8 standardized game situations. Results indicated that II-players spent significantly $(\mathrm{p} \leq 0.05)$ more time to decide $(0.92 \pm 0.2 \mathrm{~s})$ than AB-players $(0.63 \pm 0.1 \mathrm{~s})$ and to execute the solution (II: $3.01 \pm 0.4 \mathrm{~s}$; AB: 2.56 $\pm 0.3 \mathrm{~s}$ ). Also, II-players made more rule infractions (II: 7.11 \pm 1.4 ; AB: 7.71 \pm 0.7 ), more feints (II: 1.37 \pm 1.4 ; $\mathrm{AB}$ : $0.3 \pm 0.6$ ), more dribbles (II: 15.08 \pm 3.9 ; $\mathrm{AB}: 12.29 \pm 2.3$ ) and they performed less successful solutions (II: 4.42 \pm 1.5 ; AB: $5.39 \pm 1.3$ ). However, no differences were found in number of correct decisions made. Decision time, number of dribbles and situations in which they succeeded were the variables that best discriminated between II and AB-players. These results confirmed the negative influence of II on players' capacity to solve a basketball game situation. The calculated discriminant function let us establish the minimum scores from this test that indicates significant limitations on the capacity to solve a game situation. These scores are applicable to determine eligibility criteria in IIbasketball worldwide.
\end{abstract}

Keywords: Classification, eligibility systems, Paralympics, decision making.

Influencia de la discapacidad intelectual (DI) en la capacidad de los jugadores de baloncesto para resolver una situación de juego: hacia los sistemas de clasificación basados en la evidencia en baloncesto-DI

RESUMEN: El baloncesto para personas con discapacidad intelectual (DI) requiere del desarrollo de sistemas de elegibilidad basados en la evidencia que garanticen la participación en estas competiciones únicamente de deportistas con limitaciones significativas para practicar baloncesto. Además, esto es 
necesario para re incluir el baloncesto-DI en el programa Paralímpico. Para hacer esto, es necesario investigar cómo la DI impacta sobre las actividades fundamentales del baloncesto. Para cubrir esta necesidad, el objetivo de este estudio fue comparar la capacidad de resolver situaciones de juego en jugadores con y sin DI. Un test de campo se diseñó ad hoc en el que 38 jugadores de alto nivel con DI de Francia, Portugal, Australia y Japón que participaron en los Global Games (2015) y 38 jugadores sin DI participantes en competiciones Españolas, tenían que resolver 8 situaciones estandarizadas de juego. Los resultados indicaron que los jugadores con DI usaron significativamente $(\mathrm{p} \leq 0.05)$ más tiempo para decidir $(0.92 \pm 0.2 \mathrm{~s})$ que los jugadores sin DI $(0.63 \pm 0.1 \mathrm{~s})$ así como para ejecutar la solución (DI: 3.01 $\pm 0.4 \mathrm{~s}$; sin DI: 2.56 $\pm 0.3 \mathrm{~s})$. También, los jugadores con DI hicieron más infracciones del reglamento

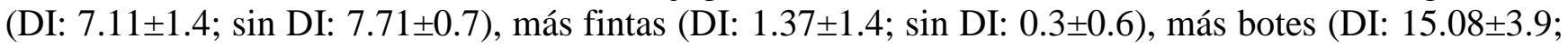
sin DI: $12.29 \pm 2.3$ ) y consiguieron menos éxito final en la solución (DI: 4.42 \pm 1.5 ; sin DI: $5.39 \pm 1.3$ ). Sin embargo, no se encontraron diferencias en el número de decisiones correctas realizadas. El tiempo de decisión, el número de botes y las situaciones solventadas con éxito fueron las variables que más discriminaron entre jugadores con y sin DI. Estos resultados confirmaron la influencia negativa de la DI sobre la capacidad para resolver una situación de juego en baloncesto. La función discriminante nos permite establecer las puntuaciones mínimas en este test que indican limitaciones significativas en la capacidad de resolver una situación de juego. Estas puntuaciones son aplicables para determinar criterios de elegibilidad en baloncesto-DI a nivel mundial.

Palabras clave: Clasificación, sistemas de elegibilidad, Paralimpiadas, toma de decisiones.

Correspondence: j.pinilla@upm.es.

Basketball is a sport in which there are a high number of interactions between teammates and their opponents in reduced time and restricted space (Araujo, Davids, \& Hristovski, 2006; Araujo \& Esteves, 2009). Therefore, players should read and decide fast during the game (Alarcón, Cárdenas, Miranda, Ureña, \& Piñar, 2010; Tenenbaum, Yuval, Elbaz, Bareli, \& Weinberg, 1993). These processes require high participation of different cognitive abilities (Jakovljevic, 1996; Karalejic \& Jakovljevic, 2008), due to this, basketball players with intellectual impairment (II) might present limitations to achieve similar performance levels compared to able-bodied (AB) players. In this line, previous studies demonstrated that II-players achieved lower shot efficiency than AB-players, they played higher game rhythm and they made more turnovers during competition (Pinilla, Pérez-Tejero, Van Biesen \& Vanlandewijck, 2015). Because these variables were found as relevant to performance success (Pérez-Tejero, Pinilla \& Vanlandewijck, 2015), II-players competing with AB-players in high level competitions might be disadvantaged. Consequently, the development of II-basketball competitions seems necessary to provide II-players the opportunity to compete in equal conditions achieving their maximum level of performance.

The Paralympic Games represent the biggest worldwide sport event for athletes with physical, visual and intellectual impairment. The International Federation for para-athletes with Intellectual Disability (INAS) and the athletes they represent were banned from Paralympic competition because the eligibility system in place was proven to have major flaws. The reinclusion of II-athletes in the Paralympics was very recent in London 2012 (Burns, 2015); however, II-basketball is not included yet in the program. One necessary requirement to reinclude II-basketball in the Paralympics is to develop an evidence-based eligibility system which ensures that only athletes with significant impact of II on basketball performance (C) Psy, Soc, \& Educ, 2015, Vol. 8(2) 
participate in specific II-competitions (IPC, 2015). To develop such a system, it is needed to investigate how II impacts on fundamental basketball activities and to identify the minimum impairment needed to significantly affect these activities (Tweedy \& Vanlandewijck, 2011).

Basketball is a sport in which tactical components (individual and collective) are relevant (Sampedro, 1999) and it requires a high decision making capacity to effectively solve the situations that occur during the game (Jiménez, Lorenzo, Sáenz-López, \& Ibáñez, 2009; Stella, Peacock, \& Chuan, 2012). Different theories in literature can be found explaining the cognitive processes involved in decision making in sport. The Operative Model of Decision Making (Gréhaigne, Godbout, \& Bouthier, 2001) highlights the relevance of perceptive processing decision making. The Information Processing Theory (Moreno, Fuentes, Del Villar, Iglesias, \& Julián, 2003) considers the decision making process being divided in two stages: a cognitive stage (perception and processing) and a motor-cognitive stadium (execution). However, other more recent theories indicated that the decision making process is not just a result of cognitive calculations comparable to computer software: also individual's preferences and contextual factors are relevant in this process (Busemeyer \& Townsend, 1993; Raab, 2002; Busemeyer \& Johnson, 2003). In addition, the Fast and Frugal Heuristic (FFH) approach of decision making (Bennis \& Pachur, 2006; Gigerenzer \& Goldstein, 1996) indicated that to solve a problem (heuristic), decisions have to be made with high speed (fast), which is given by the individual's capacity to use less information or require fewer cognitive steps (frugal). Other authors called this Intuitive Decision Making (Dane, Rockmann, \& Pratt, 2012).

One model frequently used in the literature (Jiménez, 2007; Moreno et al., 2003; Stella et al., 2012) to explain basketball decision making process is the model presented by Tenenbaum (2003; Figure 1).

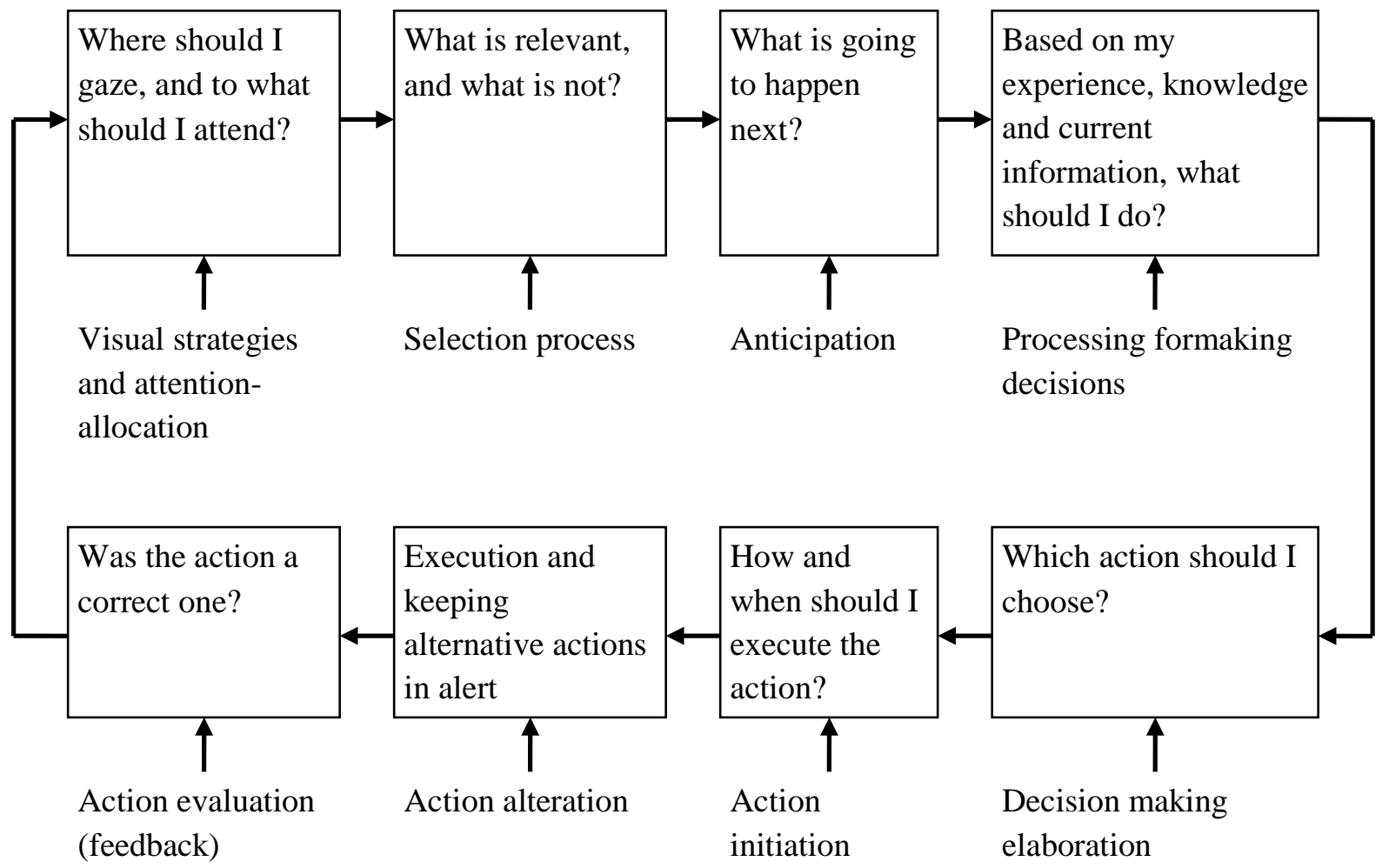

Figure 1. Decision making process and its cognitive components (Tenenbaum, 2003) 
Despite the differences found between these models, all of them agree that to solve a game situation, athletes need to follow three key fundamental stages: perception, decision and execution. These three stages require a high involvement of intellectual functioning (Alarcón et al., 2010; Tenenbaum et al., 1993). As Burns (2015) suggested, investigating the impact of II on sport performance, research should be oriented on how II influences those activities relevant to perform in a given sport that has a high cognitive load, which is the case for II basketball. For authors' knowledge, still no reference in the literature has studied this influence. Therefore, the aim of the present study was to compare II and AB basketball player's capacity to solve basketball game situations. A recent study revealed that well trained II-athletes performed significantly worse than AB-athletes in a generic cognitive test to assess executive functions and cognitive abilities relevant to sport (Van Biesen, Mactavish, McCulloch, Lenaerts \& Vanlandewijck, 2016); based on this study, it can be hypothesized that II-basketball players decide significantly slower and less effectively in realistic basketball conditions than their ABpeers.

\section{Method}

\section{Participants}

Thirty eight elite male II-basketball players (age $=26 \pm 7$ years) and a control group of thirty eight male AB-players (age $=19 \pm 7$ years) participated in this study. II-players represented four countries: France, Portugal, Australia and Japan; competing at the 2015 Global Games (Ecuador) organized by the International Federation for Para-athletes with Intellectual Disabilities (INAS). All II-players met the criteria for diagnosis of Intellectual Disability (AAIDD, 2010): significant limitations on intellectual functioning (IQ $\leq 75$ ) and on adaptive behavior manifested before the age of 18. AB-players from the control group participated in AB-competitions in Spain at regional level in two different categories: under-18 (U-18; $n=8$, age $=17 \pm 1)$ and senior $(n=30$, age $=20 \pm 3$ ). Experience and training volume was checked in all groups.

\section{Research Design}

To assess basketball player's capacity to solve basketball game situations, a field test was designed ad hoc in which the tested players had to play different standardized game situations looking for the most successful solution. To develop this test, first, 16 game situations including different 1-on-1, 2-on-1, 2-on-2 and 3-on-2situations were designed by a basketball expert (12 years of experience). These situations were blinded reviewed by four basketball professors from the Technical University of Madrid (UPM) with more than 20 years experience each one. Game situations were selected if $100 \%$ of agreement was reached on the following two criteria: (1) the game situation represented a real situation that can occur during a game and (2) there was only one clear correct decision to solve the situation: to shoot, to dribble or to pass. Final selection was composed by11 game situations: three 1-on-1 situations, three 2-on-1 situations and five 2-on-2 situations. From this selection, to explain the test, one situation was employed for demonstration (1-on-1) and two situations were used for trials (2- 
on-1 and 2-on-2). For data collection, 8 game situations were used. To administer the test, three basketball players were trained to reproduce the situations as presented in the test protocol which was previously designed and piloted by two basketball experts. According to this protocol, 1-on-1 situations were played first, followed by 2-on-1 situations and 2-on-2 situations.

Each situation was played in three stages: "ready", "set" and "play". In the "ready" position, the tested player had to hold the ball, standing in front of the basket, $60 \mathrm{~cm}$ far from the 3-point line (8.57 meters from the baseline). In this stage, defensive testers were placed on the left of the tested player and the offensive tester was placed on his right. To differentiate offensive and defensive players, colored t-shirts were used. Once the testers and the tested player were ready, the test administrator said "positions". Here, the "set" stage started and testers had to move to the position in which they had to start playing the situation. In this phase, the tested player had to keep in the "ready" position. Once the testers reached the "set" position, the test administrator made a visual signal with his hand while he said "play". In this moment, the "play" stage started; testers reproduced the situation as indicated in the protocol and the tested played had to solve the situation as fast and as accurate as possible (see figure 2).

“Ready” stage
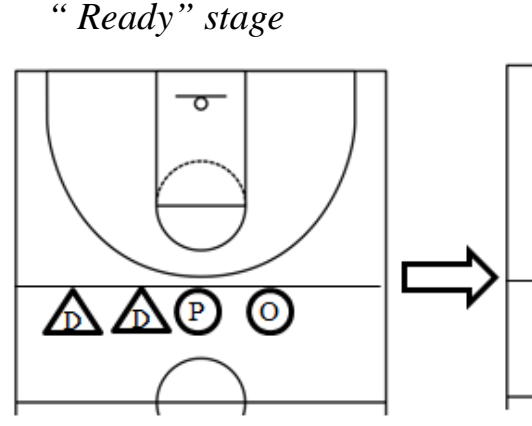

“Set” stage

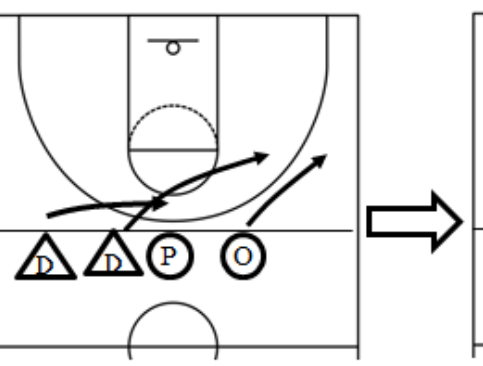

"Play" stage

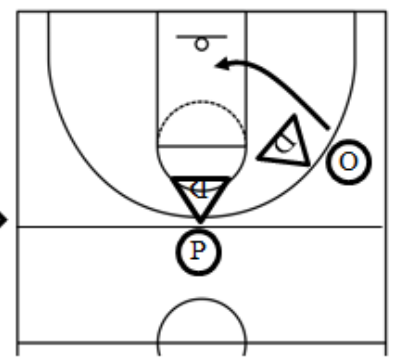

D. Defensive tester

(P) Tested Player

(O) Ofensive tester

Figure 2. Example of the three stages in a 2-on-2 situation

\section{Procedures}

To perform the test, one court, one ball, 4 colored t-shirts (2 different colors), 4 cones, one measuring tape, one video camera, one tripod, one pen, one personal data sheet and three trained testers were needed. The following personal data were collected: name, surname, birth date, country, team, position, hand preference, date, experience playing basketball (years) and training volume (hours per week and months per year). Also II-basketball player's team quality (final team classification at the 2015 Global Games) was registered. France was the best classified team from the teams participating in this study, followed by Portugal, Australia and Japan.

\section{Data Collection}

The following data were collected in each of the eight selected situations: time employed by the testers in the "set" stage, player's decision made, decision time, execution 
time, rule violations, dribbles, feints and success. Time variables were measured through video frame analysis with an accuracy of 0.04 seconds $(25 \mathrm{~Hz})$. The time used by the testers in the "set" stage was calculated from the frame in which testers started to move until the test administrator gave the hand signal. Decision time was calculated from this moment until the ball left the tested player's hands. Execution time was calculated from this moment until the ball touched the basketball ring, the ball was scored, lost or received by the offensive tester. Accuracy of the decisions was collected according to the criteria stablished in the test protocol. A successful execution was considered if the tested played scored into the basket or if a successful pass was given to the offensive tester. In addition, number of dribbles made, feints used and rule violations were collected to explore how players executed the different eight situations.

\section{Statistical Analyses}

Normal distribution of data collected was confirmed through Kolmogorov-Smirnov test. Descriptive statistics (mean and standard deviation) were calculated for all variables and a tstudent test was performed to identify differences between II and AB-players in these variables and regarding experience and training volume. Pearson correlation was calculated to explore the relationship between contextual variables and test outcome. Differences between subgroups of AB-sample regarding their level of competition were calculated through U-Mann Whitney test. Finally, a discriminant analysis was carried out and the obtained structural coefficients (SC's) from the discriminant function were used to identify the variables which best discriminated between II and AB-players performing the test (Ntoumanis, 2001). Level of significance was set at SC above $|0.30|$ (Tabachnick \& Fidell, 2005). Leave-one-out classification was conducted to validate the discriminant models (Norušis, 2004). All statistical analyses were performed using PASW statistics 20 (SPSS Inc., Chicago, IL, USA). Statistical significance was set at $P<0.05$.

\section{Ethics approval}

All participants signed an informed consent. The study was approved by INAS, IPC and the KU-Leuven ethical committee.

\section{Results}

In order to control possible effects of differences administrating the test, no differences were found in the time employed by the testers in the "set" stage when the test was administrated in $A B$ and II-players. In addition, no relationship was found between this variable and any of the player's variables performing the test.

Descriptive statistics (mean and standard deviation) and differences between II and ABplayers in the variables collected in the test are presented in table 1. AB-players decided and executed significantly faster ( $\mathrm{p} \leq 0.05$ ), they made less infractions, less feints, less dribbles and they solved successfully more game situations. No differences were found between II and ABplayers in number of correct decisions made. 
Table 1. Differences between II and AB playersperforming the test

\begin{tabular}{rccc}
\hline & II & Sig. & AB \\
\hline Mean decision time in each situation & $0.92 \mathrm{~s}(0.2)$ & $>$ & $0.63 \mathrm{~s}(0.1)$ \\
Mean execution time in each situation & $2.1 \mathrm{~s}(0.4)$ & $>$ & $1.94 \mathrm{~s}(0.2)$ \\
Mean time to solve each situation & $3.01 \mathrm{~s}(0.4)$ & $>$ & $2.56 \mathrm{~s}(0.3)$ \\
Number of correct decisions & $7.11(1.1)$ & $=$ & $7.29(0.9)$ \\
Number of feints made & $1.37(1.4)$ & $>$ & $0.3(0.6)$ \\
Number of situations with no rule infractions & $7.11(1.4)$ & $<$ & $7.71(0.7)$ \\
Number of dribbles made in the whole test & $15.08(3.9)$ & $>$ & $12.29(2.3)$ \\
Number of successful solutions & $4.42(1.5)$ & $<$ & $5.39(1.3)$ \\
\hline
\end{tabular}

Sig. $\mathrm{p} \leq 0.05$ and direction of the significance

AB- player
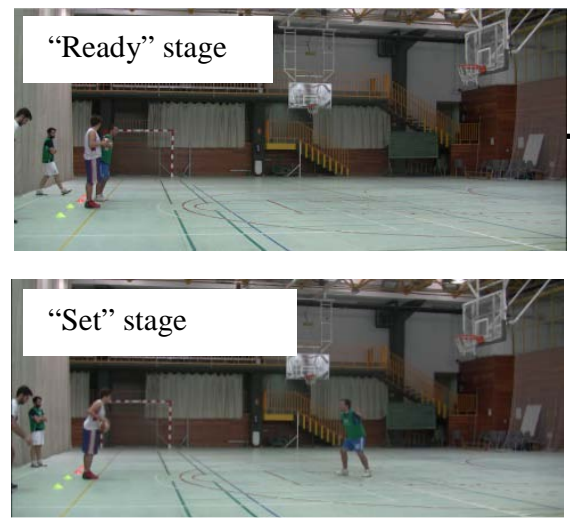

Time employed by the tester in the "set" stage. $t=2.6 \mathrm{~s}$

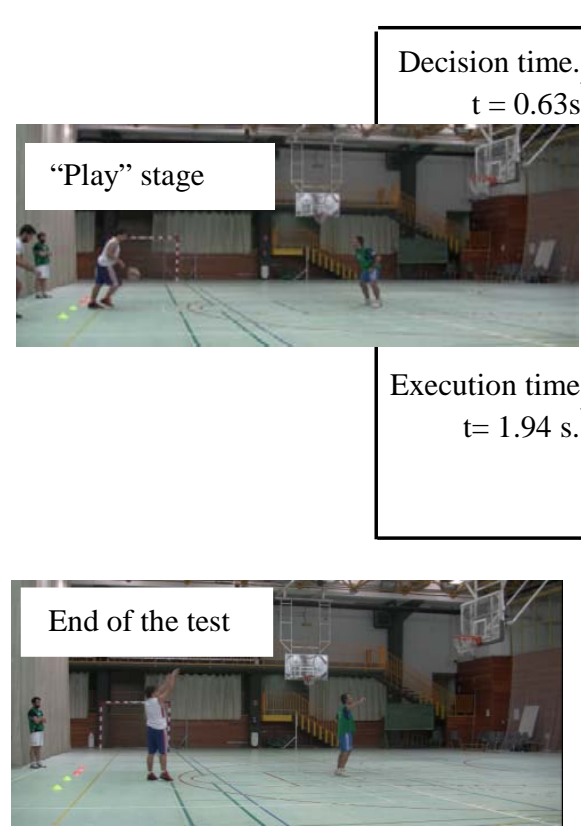

II- player
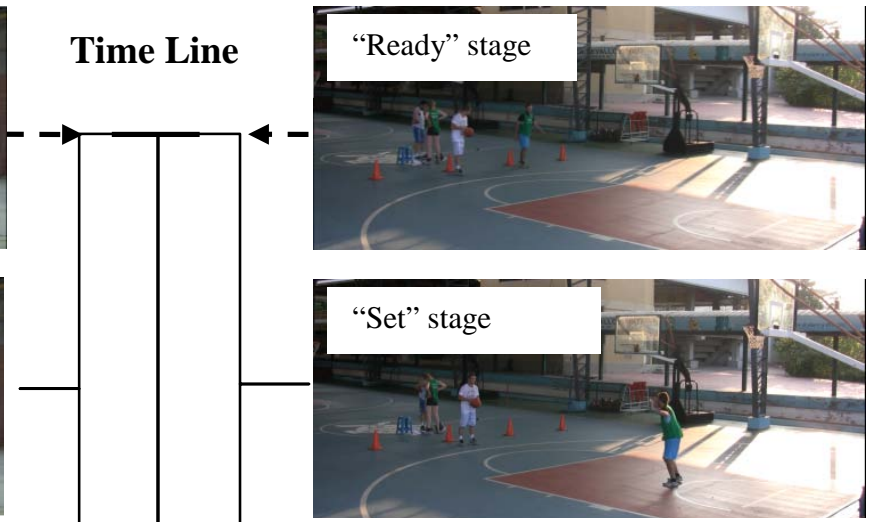

Time employed by the tester in the "set" stage. $t=2.6 \mathrm{~s}$

Decision time. $\mathrm{t}=0.92 \mathrm{~s}$

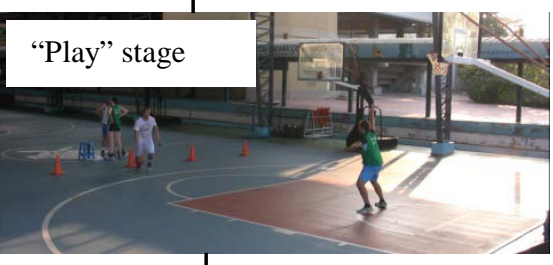

Execution time $\mathrm{t}=2.1 \mathrm{~s}$.

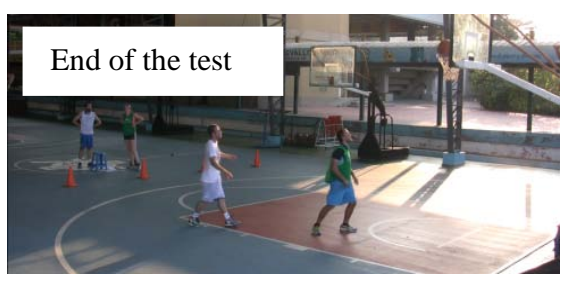

Figure 3. Time line comparing average results of II and AB-players in each situation 
Results from training volume and experience indicated that II-players played $12.4 \pm 6.2$ years, $5.8 \pm 5.6$ hours a week of training and $11.1 \pm 1.1$ months per year of training, with an accumulated experience of $2899 \pm 2545$ hours; U-18 AB-players played $4.0 \pm 2.8$ years, $4.3 \pm$ 0.5 hours a week and $9.0 \pm 0$ months per year, with an accumulated experience $582 \pm 284$ hours and senior AB-players played $9.1 \pm 2.9$ years, $5.3 \pm 1.8$ hours a week and $9.6 \pm 0.7$ months per year, with an accumulated experience $2061 \pm 1064$ hours. The effect of training volume and experience on the test outcome was checked and the significant correlations found are presented in table 2 .

Table 2. Relationship between training volume and experience with the test outcome

\begin{tabular}{lcccc}
\hline & II-players & \multicolumn{2}{c}{ AB-players } \\
Test Variables & Months / year & Years & Months/ year & Total experience \\
\hline Decision time & 0.50 & -0.48 & & \\
Execution time & & & -0.34 & -0.52 \\
Dribbles & -0.34 & & & 0.41 \\
Correct decisions & & & \\
Success & 0.40 & & \\
* Significant correlation $(\mathrm{p} \leq 0.05)$ &
\end{tabular}

In addition, the relationship between different variables from the field test was explored finding that, in II-players, number of dribbles correlated significantly $(\mathrm{p} \leq 0.05)$ with mean execution time $(r=0.75)$, mean decision time $(r=-0.34)$ and success $(r=-0.44)$. Furthermore, a significant correlation $(\mathrm{p} \leq 0.001)$ between team quality and mean decision time was found $(\mathrm{r}$ $=0.70)$. Players from France and Portugal decided significantly faster $(\mathrm{p} \leq 0.05)$ than players from Australia and Japan; however, Japan solved more game situations successfully than France and Portugal ( $\mathrm{p} \leq 0.05$ ). No relationship was observed between playing position (guard, forward and center) and test outcomes in II and AB-players.
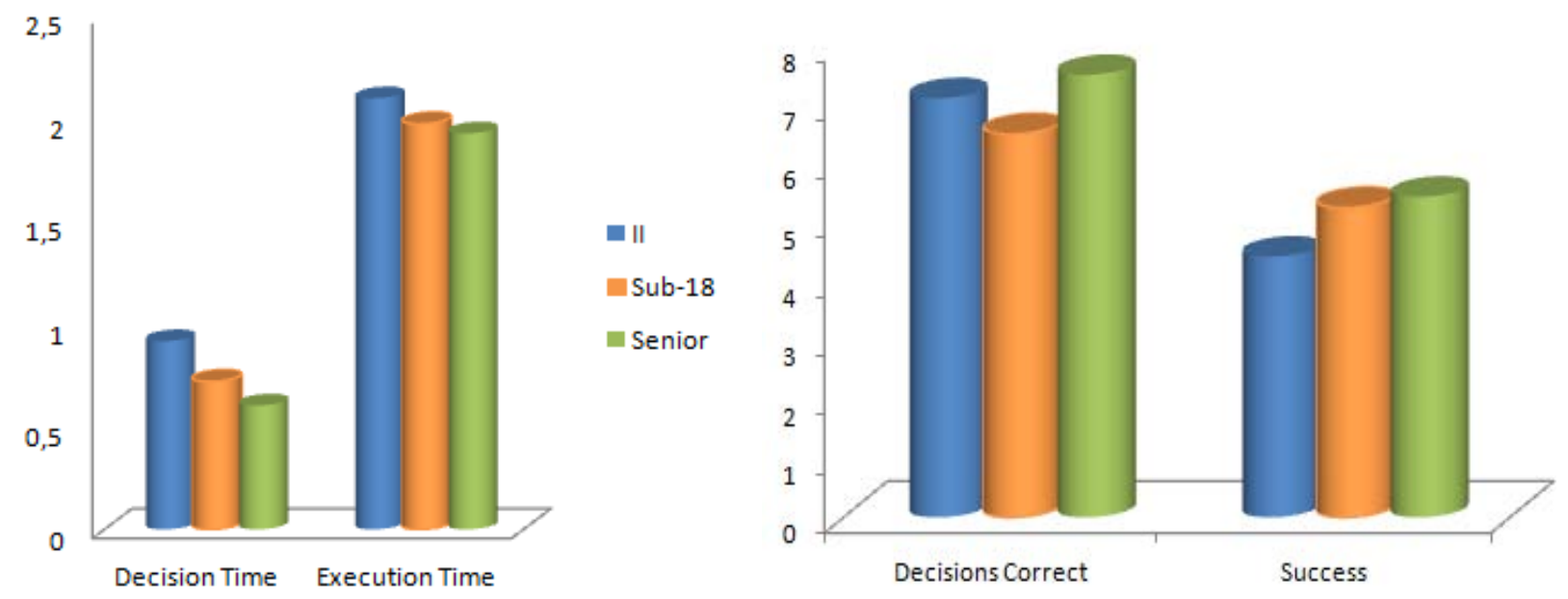

Figure 3. Differences between II and AB-players per level of competition 
The calculated discriminant function was significant $\$$ (p.001) and the canonical correlation was 0.924 . The values of the function were:

$$
\begin{aligned}
& \mathrm{D}=\mathrm{Dt} 1 * 1,756+\mathrm{Ex} 1 * 0,668+\mathrm{Dec} 1 * 0,718+\mathrm{Rl} 1 * 1,291+\mathrm{Dr} 1 * 0,324+\mathrm{Sc} 1 *- \\
& 0,406+\mathrm{Dt} 2 * 2,521+\mathrm{Ex} 2 *-1,083+\mathrm{Rl} 2 * 0,777+\mathrm{Dr} 2 * 0,486+\mathrm{Sc} 2 *-0,374+\mathrm{Dt} 3 * 3,945+\mathrm{Ex} 3 *- \\
& 0,798+\text { Dec } 3 * 0,501+\text { Dr } 3 *-0,379+\text { Sc } 3 *-0,781+\text { Dt } 4 * 0,805+E x 4 *- \\
& 0,509+\mathrm{Rl} 4 * 0,78+\mathrm{Dr} 4 * 0,694+\mathrm{Sc} 4 *-0,946+\mathrm{Dt} 5 * 0,721+\mathrm{Ex} 5 *-0,177+\mathrm{Dec} 5 * 0,303+\mathrm{Rl} 5 *- \\
& 1,122+\text { Dr5*0,383+Sc5*0,767+Dt6*0,052+Ex6*0,482+Dec6*-0,097+Dr6*-0,707+Sc6*- } \\
& 0,582+\mathrm{Dt} 7 *-0,188+\mathrm{Ex}^{*} *_{-} 0,096+\mathrm{Dec}^{*} 0,737+\mathrm{Rl} 7 *-0,195+\mathrm{Dr} 7 * 0,755+\mathrm{Sc} 7 *_{-} \\
& \text {0,508+Dt8*0,110+Ex8*-0,171+Dec8*-1,572+Rl8*1,195+Dr8*-1,128+Sc8*-0,116 -7,914 }
\end{aligned}
$$

Where Dtn = decision time in situation "n"; Exn= execution time; Decn = accuracy of the decision; Rln=rule violation; Drn= number of dribbles; Scn= success.

According to the level of competition, senior AB-players decided significantly ( $\mathrm{p} \leq 0.05$ ) better, faster and they used less dribbles solving the game situations than U-18 players. When results between II-players and both sub-groups of AB-players were compared separately, differences were higher when compared with senior players instead of U-18 players (Figure 4). Even, II-players obtained better scores in number of correct decisions than U-18 players, but these differences were not significant ( $\mathrm{p} \geq 0.05$ ).

When this function was applied in each player using the scores obtained in the test, a " $D$ value" was obtained. This value represents the proximity of player's performance in the test with the reference values from II or AB-players. When the calculated "D value" was higher than -0.0325 , the player was classified as II-player and, when it was lower, the player was classified as AB-player. The power of this function to classify II and AB-players was extremely high because it classified $98.6 \%$ of the players correctly according to their initial group of pertinence: AB or II-players.

The analysis of the SC of all the variables indicated thatthose variables with SC $\geq|0.30|$ were the variables that significantly contributed to discriminate between II and ABplayers in the test (table 3).

Table 3. Structural coefficients of the test's variables for every field test situation (1-8)

\begin{tabular}{lcccccccc}
\hline Game situation & 1 & 2 & 3 & 4 & 5 & 6 & 7 & 8 \\
\hline Decision time & $.611^{*}$ & $.783^{*}$ & $-.766^{*}$ & $.480^{*}$ & $.856^{*}$ & $.923^{*}$ & $.582^{*}$ & $-.615^{*}$ \\
Execution time & $.336^{*}$ & -.166 & -.288 & $.436^{*}$ & .209 & .068 & .248 & -.051 \\
Decision correct & .058 & .00 & $.334^{*}$ & .00 & .080 & -.114 & .168 & $.468^{*}$ \\
Dribbles & $.434^{*}$ & .010 & -.290 & $.388^{*}$ & $.402^{*}$ & -.030 & $.485^{*}$ & -.180 \\
Success & -.130 & -.242 & $.464^{*}$ & $-.833^{*}$ & .042 & -.081 & .008 & $.448^{*}$ \\
\hline Correct Decision & Shot & Dribble & Pass & Shot & Dribble & Pass & Shot & Pass \\
\hline Eigenvalue & .915 & .489 & .550 & .249 & .458 & .384 & .550 & .474 \\
Wilk's Lambda & .522 & .672 & .645 & .801 & .686 & .722 & .645 & .678 \\
Canonical Correlation & .691 & .573 & .596 & .446 & .561 & .527 & .596 & .567 \\
Chi-square & 45.82 & 28.24 & 30.89 & .446 & 26.23 & 22.91 & 30.88 & 27.36 \\
Significance & .001 & .001 & .001 & .05 & .001 & .001 & .001 & .001 \\
Reclassification & $80 \%$ & $74.7 \%$ & $82.7 \%$ & $68.5 \%$ & $78.4 \%$ & $70.7 \%$ & $80 \%$ & $73.3 \%$ \\
\hline
\end{tabular}

$* \mathrm{SC} \geq|0.30|$ 


\section{Discussion}

The aim of the present study was to compare II and AB player's capacity to solve a basketball game situation. In line with our hypothesis, II-players solved the situations less successfully and they took more time to decide and to execute the actions. However, correctness of the decisions made reached similar levels than AB-players.

Following the three common phases observed in the different models of decision making: perception, decision and execution (Gréhaigne et al., 2001); the obtained results provided insight of the influence of II in these processes involved in basketball. The lack of differences found between the time the testers used to move from the "ready" stage to the "set" stage when the test was administrated to II and AB-players ensured that visual stimuli given to the players to perceive the game situation was similar. In this test, the variable decision time assessed the time players employed in a cognitive stadium like presented in the Information Processing Theory (Moreno et al., 2003) that included the perceptive and decisional processes the players carried outsince the test administrator gave the signal and the ball left the player's hands. According to the model of decision making in sports from Tenenbaum (2003), in this time players had to use visual strategies, attention location, selection process, anticipation, process for making decisions and decision elaboration. In this time, also knowledge (French \& Thomas, 1987) and tactical skills seem to be required (Gréhaigne \& Godbout, 1995; Ibáñez, 2004) to find the best solution to the given situation. Results in this phase indicated that IIplayers, at the level of complexity presented in the standardized situations, can reach similar levels of correct decisions than AB-players; however, it seems that II negatively influences on player's capacity to process the same information as fast as AB-players.

During the execution phase, player's had to use effectively the most appropriate skills to solve the situation (Jiménez, 2007). But also, according to Tenenbaum's model (2003), once the players started the action, they had to keep in alert about the possibilities presented during the game situation. II-players spent more time than AB-players in this phase, they made more dribbles, they made more infractions and they achieved less successful solutions. Probably, II might also influence on technical proficiency of II-basketball players as it was found in II-table tennis players (Van Biesen, Mactavish, Pattyn, \& Vanlandewijck, 2012) that could explain these differences; however, as technical skills were not assesed in this study it can not be confirmed yet. Besides, according to Tenenbaum's model (2003), once player's decide, they need to continuously read the situation. As II-players required more time to process the information to decide, probably, they also needed more time to continuously read the situation during the execution. The higher number of dribbles in II-players could explain that they did this to have more time to process the information. In addition, results from II-players indicated that players who required more time to decide also required more dribbles to carry out the solution (see Table 2).

The presented limitations found in II-players to achieve AB-players outcomes in this field test confirmed II-player's limitation to solve a game situation as effectively as ABplayers, being this activity fundamental to perform in basketball (Alarcon et al., 2009; Tallir, Musch, Valcke, \& Lenoir, 2005; Tenenbaum, 2003; Trninic, Dizdar, \& Luksic, 2002). These 
results go in line with those presented by Polo, Pinilla, Pérez-Tejero, \& Vanlandewijck, (2014) that indicated that, for II-basketball coaches' opinion, II-players presented limitations especially on collective and individual offensive tactics.

The positive relationship found in AB-players between level of performance, experience and decision making capacity was in line with the findings in the literature and reinforces the validity of the abilities assessed in this test to perform basketball (Kioumourtzoglou, Derri, Tzetzis, \& Theodorakis, 1998; Kioumourtzoglou, Kourtessis, Michalopoulou, \& Derri, 1998; Tenenbaum, 2003). However, in II-players, contrary to what it might be expected; no relationship was found between experience and the test outcomes. Probably, other factors such as the diversity of the impairment's etiology or degree of impairment (Armatas, 2009) might have more influence on decision making capacity than experience.

The relationship found between team quality, decision time and success solving the different game situations seemed to indicate that in II-basketball, success is more related with speed than accuracy making decisions. Moreover, decision time is the only variable whose structural coefficient contributes significantly in all of the situations presented in the test (Table 3). From the participating teams in this study, those worse classified solved the situations more successfully than those teams better classified; however, these teams decided faster. These evidences seem to go in line with the analysis of game-related statistics made in elite IIbasketball competitions in which it was found that rhythm was faster, shot efficiency was lower and players committed more turnovers and steals per game compared with similar studies in AB-competitions (Pérez-Tejero, Pinilla, \& Vanlandewijck, 2015; Pinilla, Pérez-Tejero, Van Biesen, \& Vanlandewijck, 2015).

The development of this field test and the results obtained are relevant for the development of II-basketball eligibility systems. As it is required for classification in Parasport, eligibility systems must be sport-specific, and for this, specific assessment tools must be designed to evaluate the impact of II on the fundamental activities of each sport (Tweedy \& Vanlandewijck, 2011). The presented results confirm the negative influence of II to solve a basketball game situation on the field, in addition, the discriminant analysis performed confirmed the validity of each game situation to discriminate II and AB-players according to the abilities assessed in this test. Moreover, the calculated discriminant function let us determine, in base of the evidences analyzed, which is the minimum impairment required to present significant limitations in the capacity to solve a basketball game situation comparing with the control group of AB-players. To establish this "minimum impairment" is the final aim of the development of eligibility systems, which is needed to guarantee equal opportunities to success of all athletes participating in Para-sport. Although, future research is needed to investigate the relationship between the abilities assessed in this study with outcome from the competition and also to investigate the influence of II on other basketball fundamental activities; results from this study let us to establish a first specific eligibility criteria in basketball that can be applicable worldwide. In addition, the development of these criteria might strongly contribute to re-include II-basketball in the Paralympic Games. 


\section{Conclusions}

Findings in the present study confirmed that II-basketball players presented significant limitations on their capacity to solve basketball game situations compared with their AB-peers. This activity is fundamental to perform in basketball and it requires athletes to perceive the situation, to decide and to execute effectively. Results in this study highlighted that II-players spent more time making decisions, executing solutions and their success solving the situations was lower. Multivariate analysis let us use this test to classify II and AB players according to their capacity to solve a game situation, being these results applicable to determine specific eligibility criteria in II-basketball. Establishing these criteria, equal opportunities to success in future II-basketball competitions could be ensure and also, it could contribute to re-include IIbasketball in the Paralympic Program.

\section{Acknowledgments}

The present study has the endorsement and the support of IPC and INAS. In addition, this study is part of the research project "Assessment tools development of sport intelligence: applications to international basketball eligibility systems for players with intellectual disability", subsidized by the Spanish Ministry of Economy and Competitiveness (reference number DEP2012-33649).

\section{References}

AAIDD. (2010). Intellectual disability, definition, classification and systems of support. Washington DC: American Association on intellectual and developmental disabilities(AAIDD).

Alarcon, F., Cardenas, D., Miranda, M. T., Urena, N., Pinar, M. I., \& Torre, E. (2009). Effect of a training program on the improvement of basketball players'decision making. [Article]. Revista De Psicologia Del Deporte, 18, 403-407.

Alarcón, F., Cárdenas, D., Miranda, M. T., Ureña, N., \& Piñar, M. I. (2010). La mejora de la capacidad de atención selectiva del jugador de baloncesto a través de la enseñanza orientada al aprendizaje táctico. Cultura, Ciencia y Deporte, 5(14), 101-108.

Araujo, D., Davids, K., \& Hristovski, R. (2006). The ecological dynamics of decision making in sport. Psychology of Sport and Exercise, 7(6), 653-676.

Araujo, D., \& Esteves, P. (2009). The irreducible variability of decision making in basketball. In A. Lorenzo, S. Ibáñez \& E. Ortega (Eds.), Aportaciones Teóricas y Prácticas para el Baloncesto del Futuro (pp. 171-181): Wanceulen.

Armatas, V. (2009). Mental retardation: definitions, etiology, epidemiology and diagnosis. Journal of Sport and Health Research, 1(2), 112-122.

Bennis, W. M., \& Pachur, T. (2006). Fast and frugal heuristics in sports. Psychology of Sport and Exercise, 7(6), 611-629.

Burns, J. (2015). The impact of intellectual disabilities on elite sports performance. International Review of Sport and Exercise Psychology. 
Busemeyer, J., \& Townsend, J. T. (1993). Decision field theory: a dynamic-cognitive approach to decision making in an uncertain environment. . Psychological Review, 100, 432-459.

Busemeyer, J. R., \& Johnson, J. G. (2003). Computational models of decision making. In D. Koehler \& N. Harvey (Eds.), Handbook of judgment and decision making. Indiana University: Blackwell Publishing Co.

Dane, E., Rockmann, K. W., \& Pratt, M. G. (2012). When should I trust my gut? Linking domain expertise to intuitive decision-making effectiveness. Organizational Behavior and Human Decision Processes, 119(2), 187-194.

French, K. E., \& Thomas, J. R. (1987). The relation of knowledge development to children's basketball performance. Journal of Sport Psychology, 9(1), 15-32.

Gigerenzer, G., \& Goldstein, D. G. (1996). Reasoning the fast and frugal way: Models of bounded rationality. Psychological Review, 103, 650-669.

Gréhaigne, J. F., \& Godbout, P. (1995). Tactical knowledge in team sports from a constructivist and cognitivist perspective. Quest, 47, 490-505.

Gréhaigne, J. F., Godbout, P., \& Bouthier, D. (2001). The teaching and learning of decision making in team sports. Quest, 53, 59-76.

Ibáñez, S. J. (2004). El entrenamiento de las conductas táctico-técnicas: desde situaciones individuales a colectivas. In A. C. Jiménez, C. López \& A. López (Eds.), II Curso de didáctica del baloncesto en las etapas de iniciación (pp. 97-121). Madrid: Instituto Nacional de Educación Física.

IPC. (2015). IPC Classification code. Bonn.

Jakovljevic, S. (1996). Simultaneous influence of the specific basketball motoric and cognitive abilities on success of basketball. Facta Universitatis: Series Physical Education \& Sport, 1(3), 91-98.

Jiménez, A. C. (2007). Análisis de la toma de decisión en los deportes colectivos. Estrategias de las jugadoras aleros de baloncesto en posesión del balón. Sevilla: Wanceulen editprial deportiva, S.L.

Jiménez, A. C., Lorenzo, A., Sáenz-López, P., \& Ibáñez, S. (2009). Decision-Making of spanish female basketball team players while they are competing. Revista de Psicología del Deporte, 18(3), 369-373.

Karalejic, M., \& Jakovljevic, S. (2008). Cognitive abilities of young basketball players and their actual success. Physical Culture, 62, 117-123.

Kioumourtzoglou, E., Derri, V., Tzetzis, G., \& Theodorakis, Y. (1998). Cognitive, perceptual, and motor abilities in skilled basketball performance. Perceptual \& Motor Skills, 86(3 Part 1), 771-786.

Kioumourtzoglou, E., Kourtessis, T., Michalopoulou, M., \& Derri, V. (1998). Diferences in several perceptual abilities between experts and novices in basketball, volleyball and water-polo. Perceptual \& Motor Skills, 86(899-912).

Moreno, P., Fuentes, J. P., Del Villar, F., Iglesias, D., \& Julián, J. A. (2003). Estudio de los procesos cognitivos desarrollados por el deportista durante la toma de decisiones. Apunts, 73, 24-29.

Norušis, M. J. (2004). SPSS 13.0: Advanced statistical procedures compariums. Ennglowood Cliffs: Pretince-Hall. 
Ntoumanis, N. (2001). A step-by-step guide to SPSS for sport and exercise studies. London: Ed. Routledge.

Pérez-Tejero, J., Pinilla, J., \& Vanlandewijck, Y. (2015). Perfil del rendimiento en el campeonato del mundo de baloncesto (Ankara 2013) para personas con discapacidad intelectual: Implicaciones en el sistema de elegibilidad. Revista Iberoamericana de Psicología del Ejercicio y el Deporte, 10(2), 187-192.

Pinilla, J., Pérez-Tejero, J., Van Biesen, D., \& Vanlandewijck, Y. (2015). Performance variability in basketball players with intellectual impairment: Ankara World Championships 2013 analysis. Revista de Psicología del Deporte, 24 (suppl. 1), 77-83.

Polo, I., Pinilla, J., Pérez-Tejero, J., \& Vanlandewijck, Y. (2014). Coaches' opinion about game difficulties experienced by basketball players with intellectual disability. Paper presented at the European Congress of Adapted Physical Activity, Madrid.

Raab, M. (2002). T-ECHO: model of decision making to explain behaviour in experiments and simulations under time pressure. Psychology of Sport and Exercise, 3, 151-171.

Sampedro, J. (1999). Fundamentos de la Táctica deportiva. Análisis de la estrategia de los deportes. Madrid: Gymnos.

Stella, N. Y., Peacock, J. B., \& Chuan, T. K. (2012). Evaluating decisions made in common basketball game scenarios. 2012 Southeast Asian Network of Ergonomics Societies Conference (SEANES), 1-5. doi: 10.1109/seanes.2012.6299607

Tabachnick, B. G., \& Fidell, L. S. (2005). Using multivariate statistics. New York: Harper Collins.

Tallir, I. B., Musch, E., Valcke, M., \& Lenoir, M. (2005). Effects of two instructional approaches for basketball on decision-making and recognition ability. International Journal of Sport Psychology, 36(2), 107-126.

Tenenbaum, G. (2003). Expert athletes: an integrated approach to decision making In J. L. Starkes \& K. A. Ericsson (Eds.), Expert Performance in Sports: Advances in Research on Sport Expertise (pp. 191-218). United States of America: Human Kinetics.

Tenenbaum, G., Yuval, R., Elbaz, G., Bareli, M., \& Weinberg, R. (1993). The relationship between cognitive characteristics and decision-making. Canadian Journal of Applied Physiology-Revue Canadienne De Physiologie Appliquee, 18(1), 48-62.

Trninic, S., Dizdar, D., \& Luksic, E. (2002). Differences between winning and defeated top quality basketball teams in final tournaments of European club championship. Coll Antropol, 26(2), 521-531.

Tweedy, S. M., \& Vanlandewijck, Y. C. (2011). International Paralympic Committee position stand-background and scientific principles of classification in Paralympic sport. British Journal of Sports Medicine, 45(4), 259-269.

Van Biesen, D., Mactavish, J., McCulloch, K., Lenaerts, L. \& Vanlandewijck, Y. (2016). Cognitive profile of young well-trained athletes with intellectual disabilities. Research in developmental disabilities, doi: 10.1016/j.ridd.2016.03.004. [Published on-lin first: $18^{\text {th }}$ March 2016].

Van Biesen, D., Mactavish, J., Pattyn, N., \& Vanlandewijck, Y. (2012). Technical proficiency among table tennis players with and without intellectual disabilities. Human movement science, 31, 1517-1528. 